\title{
Peran Fraud Triangle dalam Mendeteksi Financial Statement Fraud di Perusahaan Perbankan ASEAN
}

\author{
Yuliana Pertiwi Yuwono' \\ Fakultas Ekonomi dan Bisnis \\ Universitas Ciputra, Indonesia
}

\author{
Maria Assumpta Evi Marlina² \\ Fakultas Ekonomi dan Bisnis \\ Universitas Ciputra, Indonesia
}

\begin{abstract}
Surel : yulianaapertiwi10@gmail.com
ABSTRAK

Penelitian bertujuan untuk mengetahui pengaruh fraud triangle theory terhadap Financial statement fraud. Populasi dalam penelitian adalah perusahaan perbankan komersial non-syariah yang terdaftar di SGX, MYX, SET, PSE dan IDX. Teknik pengambilan sampel menggunakan purposive sampling. Total sampel dalam penelitian sebesar 66 perusahaan perbankan komersial non-syariah. Metode analisis data yang digunakan adalah regresi linier berganda. Hasil penelitian membuktikan bahwa Financial target dan change of auditor berpengaruh positif terhadap Financial statement fraud sedangkan external pressure berpengaruh negatif terhadap Financial statement fraud. Financial stability dan ineffective monitoring tidak berpengaruh terhadap Financial statement fraud. Penelitian ini dapat digunakan sebagai acuan oleh investor, masyarakat, pemerintahan dan pengguna informasi laporan keuangan lainnya agar dapat mendeteksi Financial statement fraud melalui fraud triangle theory.
\end{abstract}
Kata Kunci: Penipuan Laporan Keuangan; Manajemen Pendapatan; Fraud Triangle.

The Role of the Fraud Triangle in Detecting Fraud Financial Statement in ASEAN Banking Companies$$
\text { ABSTRACT }
$$

This research aims to determine the effect of fraud triangle theory toward Financial statement fraud. Financial statement fraud is proxied by earnings management. Population in this study is non-Islamic commercial banking companies listed on SGX, MYX, SET, PSE and IDX. The sampling technique used purposive sampling. The total sample in the study was 66 non-Islamic commercial banking companies. The data analysis method used is multiple linear regression. The research results proved that Financial targets and change of auditors had a positive effect on Financial statement fraud while external pressure had a negative effect on Financial statement fraud. Financial stability and ineffective monitoring had no effect on Financial statement fraud. This research can be used as a reference by investors, the public, government and users of other financial statement information in order to detect Financial statement fraud through the fraud triangle theory.

Keywords: $\quad$ Financial statement fraud; Earnings Management; Fraud Triangle.
}

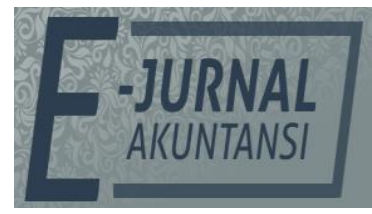

e-ISSN 2302-8556

Vol. 31 No. 3

Denpasar, Maret 2021

Hal. 713-730

DOI:

10.24843/EJA.2021.v31.i03.p15

PENGUTIPAN:

Yuwono, Y.P., \& Marlina,

M.A.E. (2021). Peran Fraud

Triangle dalam Mendeteksi

Financial Statement Fraud Di

Perusahaan Perbankan

ASEAN. E-Jurnal Akuntansi, 31(3), 713-730

RIWAYAT ARTIKEL:

Artikel Masuk:

10 Desember 2020

Artikel Diterima: 25 Maret 2021

Artikel dapat diakses : https://ojs.unud.ac.id/index.php/Akuntansi/index 


\section{PENDAHULUAN}

Menurut Asmah et al. (2020) menyatakan bahwa, tindakan kecurangan tidak dapat dihindari oleh semua perusahaan dengan tujuan untuk memanfaatkan kondisi perekonomian yang sedang berlangsung. Kondisi perekonomian di ASEAN saat ini diwarnai dengan persaingan ketat yang tidak dapat dihindari oleh industri perbankan. Hal tersebut disebabkan oleh munculnya ABIF (ASEAN Banking Integration Framework) yang merupakan salah satu agenda integrasi ekonomi masyarakat ASEAN. Terdapat beberapa syarat yang harus dipenuhi oleh perbankan untuk menjadi anggota ABIF. Syarat tersebut termuat dalam QABs (Qualified ASEAN Banks) diantaranya adalah bank yang memiliki modal kuat, pengelolaan yang baik, berdaya tahan tinggi dan memenuhi prinsip kehatihatian sesuai dengan standar internasional yang berlaku (Bank Indonesia, Desember 31, 2014). Perbankan yang tidak siap menghadapi integrasi ekonomi melalui persyaratan QABs akan berdampak pada terganggunya perekonomian negara (Kemu, 2017). Hal tersebut tentunya dapat memicu perbankan untuk melakukan segala cara agar tidak mengganggu perekonomian negara, salah satunya dengan melakukan Financial statement fraud.

Berdasarkan ISA No. 240 (2009) persaingan yang ketat dapat memicu terjadinya Financial statement fraud. Menurut Ventouri (2018) menyatakan bahwa persaingan akibat integrasi ekonomi memicu peningkatan pengambilan resiko oleh perbankan. Peningkatan pengambilan resiko tersebut terjadi karena adanya pressure dari perusahaan untuk terus bersaing. Oleh karena itu, munculnya ABIF melalui persyaratan QABs dapat memicu perbankan untuk melakukan Financial statement fraud.

Berdasarkan survei yang dilakukan oleh KPMG (2019) menunjukkan bahwa tindakan fraud meningkat selama tahun 2015 - 2018. Tindakan fraud yang meningkat tersebut sesuai dengan laporan yang dikeluarkan oleh ACFE (Association of Certified Fraud Examiners) (2020) dalam Report to the Nation yang melaporkan bahwa 2.504 tindak kecurangan telah terjadi di 125 negara dengan rata-rata kerugian sebesar USD 1.509.000. ACFE (2020) melaporkan bahwa tindakan fraud terbesar disebabkan oleh Financial statement fraud dengan jumlah kerugian sebesar USD 954.000. Laporan ACFE (2020) menunjukkan bahwa sebanyak 386 kasus Financial statement fraud terjadi di industri perbankan dengan rata-rata kerugian sebesar USD 100.000. Posisi kedua ditempati oleh industri pemerintahan, yaitu 195 Financial statement fraud dengan rata-rata kerugian sebesar USD 100.000. Posisi ketiga ditempati oleh industri manufaktur, yaitu 185 Financial statement fraud dengan rata-rata kerugian sebesar USD 198.000.

Financial statement fraud merupakan tindakan ilegal karena dapat menyesatkan pengguna laporan keuangan (Lokanan \& Sharma, 2018). Berdasarkan laporan ACFE (2020) Financial statement fraud dapat berupa pengakuan laba yang tidak sesuai dengan laporan keuangan atau disebut sebagai earnings management. Earnings management memberikan pelaporan yang palsu atau tidak reliable sehingga menyebabkan investor salah mengambil keputusan (Kurniawansyah, 2018). Perusahaan perbankan dapat memanfaatkan komponen LLP (loan loss provisions) untuk melakukan earnings management (Vishanani et al., 2019). LLP merupakan komponen yang material dan bersifat subjektif sehingga dapat dimanfaatkan oleh manajer untuk melakukan Financial 
statement fraud (Mcnichols, 2018). Selain itu, karena sifatnya yang subjektif dapat menambah peluang bagi perusahaan perbankan untuk melakukan Financial statement fraud melalui pengelolaan jumlah LLP.

Beberapa kasus Financial statement fraud telah terjadi di beberapa negara ASEAN. Salah satu contoh Financial statement fraud terjadi di Indonesia dan Malaysia. Financial statement fraud di Indonesia terjadi pada tahun 2018 yang melibatkan PT Bank Bukopin, Tbk. Tindakan tersebut menyebabkan PT Bank Bukopin, Tbk. harus melakukan revisi laporan keuangannya di tahun 2015, 2016 dan 2017. Revisi atas laporan keuangan terjadi karena adanya penggelembungan laba akibat modifikasi kartu kredit sehingga menyebabkan penurunan laba bersih dari Rp 1,08 triliun menjadi Rp 183,6 miliar (Banjarnahor, 2018).

Kasus Financial statement fraud juga terjadi di Malaysia. Kasus tersebut terjadi pada tahun 2015 dan melibatkan perusahaan milik negara yaitu 1MDB. Kasus ini melibatkan change of auditor yang dilakukan oleh 1MDB untuk menutupi Financial statement fraud yang dilakukan. Financial statement fraud yang terjadi menyebabkan laporan auditor Deloitte atas laporan keuangan 1MDB tahun 2013 dicabut (Zainul \& Achariam, 2020). Selain itu, kasus ini juga menyebabkan kehilangan kepercayaan masyarakat terhadap auditor dan pemerintahan.

Terkuaknya beberapa kasus tersebut menjadikan Financial statement fraud sebagai fenomena besar yang harus diatasi. Cara mengatasi Financial statement fraud dapat dilakukan melalui pendekatan fraud triangle theory. Fraud triangle theory memiliki 3 komponen yang saling berhubungan yaitu pressure, opportunity dan rationalization (Cressey, 1953). Berdasarkan ISA (International Standard On Auditing) No. 240 (2009) motif seseorang melakukan Financial statement fraud dapat terjadi karena adanya pressure yang timbul, opportunity yang memberikan ruang dan rationalization wujud pembenaran tidakan yang dilakukan.

Pendeteksian Financial statement fraud melalui fraud triangle theory tidak dapat secara langsung diteliti. Oleh karena itu, diperlukan proksi untuk mendeteksi Financial statement fraud melalui fraud triangle theory. Pertama, pressure diproksikan oleh Financial stability. Pressure yang disebabkan oleh Financial stability dalam perusahaan perbankan dapat timbul karena adanya persaingan yang ketat sehingga memicu perbankan untuk bertindak kompetitif (Selvarajan 2019, Dao Ha et al., 2019). Financial stability dalam perbankan dapat diukur menggunakan rasio kecukupan modal. Perbankan harus memenuhi rasio minimum kecukupan modal sebsar 8\% yang ditetapkan oleh BIS (2001) agar tidak mengganggu stabilitas perekonomian. Hal tersebut menimbulkan pressure bagi manajer sehingga dapat memicu terjadinya Financial statement fraud melalui earnings management. Penelitian yang dilakukan oleh Hidayatullah \& Praptoyo (2018) membuktikan bahwa Financial stability berpengaruh negatif terhadap Financial statement fraud, karena ketika perbankan tidak mampu mencapai rasio minimum kecukupan modal sebesar 8\% dapat memicu manajer untuk melakukan Financial statement fraud. Selain itu, ketika perbankan telah melampaui rasio minimum, maka sudah menjadi tanggungjawab manajer untuk mempertahankan rasio kecukupan modal yang diperoleh.

Proksi pressure yang kedua adalah Financial target. Berdasarkan ISA No. 240 (2009) Financial target dapat terjadi karena adanya pressure yang berlebihan 
dari pihak manajemen perusahaan. Financial target dapat menimbulkan pressure karena manajer harus memenuhi target yang telah ditetapkan. Berdasarkan ISA No. 240 (2009) target yang ditetapkan oleh perusahaan dapat berupa rasio profitabilitas. Oleh karena itu, pengukuran Financial target dapat menggunakan rasio ROA (Return on Asset). ROA dapat digunakan untuk mengukur keefektifan perusahaan dalam menggunakan asetnya untuk memaksimalkan laba (Rochmadhona et al., 2018). Sedangkan, investor akan lebih menyukai laba perusahaan yang stabil, sehingga memicu manajer untuk melakukan Financial statement fraud melalui earnings management. Penelitian yang dilakukan oleh Septriani \& Handayani (2018) menunjukkan bahwa Financial target berpengaruh positif terhadap Financial statement fraud, karena semakin tinggi target yang ditetapkan oleh perusahaan akan menimbulkan pressure bagi manajer yang akhirnya memicu Financial statement fraud.

Proksi pressure yang ketiga adalah external pressure. External pressure timbul karena adanya persaingan yang ketat sehingga manajer harus mencari dana tambahan dari pihak ketiga (Septriani \& Handayani, 2018) dan (Yesriani \& Rahayu, 2017). Persaingan yang ketat tersebut dapat memberikan efek negatif bagi perekonomian sehingga menyebabkan terganggunya stabilitas ekonomi (Husen, 2018) dan (Ozili \& Thankom, 2018). Pengukuran external pressure dapat menggunakan rasio LEV. Rasio LEV yang semakin tinggi berarti perusahaan menjaminkan simpanan nasabah yang diperoleh dengan total aset yang lebih kecil (Mangeka \& Rahayu, 2020). Hal tersebut tentunya tidak diperkenankan terjadi karena dapat mengganggu stabilitas ekonomi. Oleh karena itu, demi menjaga stabilitas ekonomi maka manajer melakukan Financial statement fraud melalui earnings management. Penelitian yang dilakukan oleh Yesriani \& Rahayu (2017) dan Achmad \& Pamungkas (2018) membuktikan bahwa external pressure berpengaruh positif terhadap Financial statement fraud.

Opportunity merupakan ruang yang dapat dimanfaatkan oleh manajer untuk melakukan Financial statement fraud (Wu \& Wang, 2019). Berdasarkan ISA No. 240 (2009) salah satu bentuk opportunity adalah ineffective monitoring yang disebabkan oleh sistem pengendalian manajemen yang buruk. Hal tersebut tentunya dapat dimanfaatkan oleh manajer untuk melakukan Financial statement fraud (Utama et al., 2018). Peran dewan komisaris independen adalah mengawasi perusahaan agar tidak terjadi penyimpangan (Ramly et al., 2017). Ineffective monitoring dapat terjadi apabila dewan komisaris independen tidak menjalankan tugasnya dengan baik dan jumlah dewan komisaris independen yang tidak sesuai peraturan yang berlaku (Ghafoor et al., 2018). Hal tersebut akhirnya memberikan ruang bagi manajer untuk melakukan Financial statement fraud melalui earnings management. Penelitian yang dilakukan oleh Ghafoor et al. (2018) dan Septriani \& Handayani (2018) membuktikan bahwa ineffective monitoring berpengaruh negatif terhadap Financial statement fraud karena, kurangnya jumlah dewan komisaris independen sehingga tidak dapat mendeteksi terjadinya Financial statement fraud.

Berdasarkan ISA No. 240 (2009) rationalization merupakan sikap seseorang saat melakukan Financial statement fraud. Sikap tersebut sebagai bentuk pembenaran atas tindakan yang dilakukannya (Utama et al., 2018). Pernyataan tersebut juga didukung oleh Vousinas (2019) yang menyatakan bahwa 
rationalization merupakan motivasi seseorang untuk membenarkan dirinya atas tindakan kejahatan yang dilakukan. Rationalization tergambar dalam hubungan manajer dan auditor (Ghafoor et al., 2018). Berdasarkan SAS No. 99 (2002) hubungan manajer dan auditor terjadi saat proses pengauditan yang akhirnya menimbulkan perselisihan karena adanya perbedaan kepentingan. Perbedaan kepentingan biasanya dalam hal pengakuan laba yang tidak sesuai dengan laporan keuangan. Hal tersebut yang memotivasi manajer untuk melakukan change of auditor karena ingin menutupi Financial statement fraud melalui earnings management. Penelitian yang dilakukan oleh Ghafoor et al. (2018) dan Utama et al. (2018) membuktikan bahwa change of auditor berpengaruh positif terhadap Financial statement fraud karena, semakin sering perusahaan melakukan change of auditor maka membuktikan bahwa perusahaan berusaha menutupi Financial statement fraud yang dilakukannya.

Subjek penelitian ini adalah perusahan perbankan di Singapura, Malaysia, Thailand, Filipina dan Indonesia selama periode 2015 - 2019. Alasan pemilihan negara Singapura, Malaysia, Thailand, Filipina dan Indonesia karena kelima negara tersebut yang paling siap menghadapi integrasi ekonomi masyarakat ASEAN sekaligus penerapan ABIF pertama kali dilakukan pada kelima negara tersebut (Ventouri, 2018). Oleh karena itu, tingkat persaingan di Singapura, Malaysia, Thailand, Filipina dan Indonesia akan meningkat dan dapat memicu terjadinya Financial statement fraud. Selain itu, menurut $15^{\text {th }}$ Global Fraud Survey yang dilakukan oleh Ernst \& Young (2018) menunjukkan bahwa kasus kecurangan lebih banyak terjadi di kawasan negara berkembang seperti negara-negara ASEAN. Pemilihan perusahaan perbankan didasari atas laporan ACFE (2020) yang menyatakan bahwa industri perbankan yang paling tinggi melakukan Financial statement fraud. Sehingga, hal tersebut menjadi motivasi penulis dalam melakukan penelitian di sektor industri perbankan.

Penelitian ini dapat memberikan manfaat bagi akademisi terkait tambahan wawasan praktik Financial statement fraud di industri perbankan ASEAN dengan pendekatan fraud triangle theory. Penelitian juga dapat memberikan manfaat bagi investor berupa referensi terkait Financial statement fraud yang terjadi di industri perbankan agar tidak salah menginvestasikan uang. Manfaat penelitian ini juga dapat membantu pemerintah untuk lebih berhati-hati dengan Financial statement fraud yang dilakukan oleh perusahaan perbankan.

Financial stability merupakan keadaan perusahaan yang stabil dan jauh dari gangguan masalah. Berdasarkan ISA No. 240 (2009) masalah Financial stability dapat timbul karena adanya persaingan yang ketat, peraturan akuntansi atau perundang-undangan dan adanya perubahan teknologi. Selain itu, Financial stability dapat timbul karena adanya gangguan kondisi perekonomian dan industri secara keseluruhan (Yesriani \& Rahayu, 2017). Pengukuran Financial stability pada perusahaan perbankan dapat menggunakan rasio kecukupan modal (Noman et al., 2018)

Rasio kecukupan modal digunakan oleh perbankan untuk menunjukkan kecukupan dana perusahaan dan menampung resiko kerugian akibat kegiatan operasional bank (Embuningthyas et al., 2018). Peraturan rasio minimum kecukupan modal harus dipatuhi oleh setiap bank di dunia agar tidak menggangu stabilitas perekonomian. Berdasarkan data yang dikeluarkan oleh 
perusahaan data analisis Hongkong, rata-rata rasio kecukupan modal di Singapura, Malaysia, Thailand, Filipina dan Indonesia selama tahun 2013 - 2019 telah di atas $8 \%$ (Ceic Data, 2020). Hal tersebut tentunya dapat menimbulkan pressure bagi manajer yang memicu terjadinya Financial statement fraud melalui earnings management. Perusahaan dapat melakukan earnings management melalui pengelolaan jumlah LLP. Embuningthyas et al. (2018) menyatakan bahwa Financial stability yang diproksikan melalui rasio kecukupan modal berpengaruh terhadap Financial statement fraud. Penelitian yang dilakukan oleh Hidayatullah \& Praptoyo (2018) menunjukkan bahwa Financial stability berpengaruh negatif terhadap Financial statement fraud karena manajer akan semakin tertekan apabila tidak mampu mencapai rasio minimum kecukupan modal. Berdasarkan penjelasan di atas maka dapat ditarik hipotesis sebagai berikut.

$\mathrm{H}_{1}$ : Financial stability berpengaruh negatif terhadap Financial statement fraud.

Berdasarkan ISA No. 240 (2009) Financial target dapat terjadi karena adanya pressure yang berlebihan dari pihak manajemen perusahaan dalam menetapkan target perusahaan. Alasan penetapan target yang tinggi karena adanya persaingan yang ketat sehingga perbankan berlomba-lomba menetapkan target yang tinggi dengan tujuan menarik perhatian investor. Investor cenderung menyukai laba yang stabil atau tidak fluktiatif (Dewi \& Eveline, 2017). Oleh karena itu, manajer berusaha melakukan earnings management melalui pengelolaan jumlah LLP. Alasannya karena manajer dapat dengan leluasa menghasilkan laba perusahaan agar sesuai dengan keinginan investor. Hal tersebut tentunya akan memicu terjadinya Financial statement fraud.

ROA merupakan salah satu indikator yang mengukur rasio profitabilitas perusahaan perbankan (Septriani \& Handayani, 2018). ROA biasanya digunakan perusahaan untuk menjadi patokan Financial target. Alasannya karena semakin tinggi ROA maka laba yang dihasilkan perusahaan juga semakin tinggi, yang artinya perusahaan dapat mengelola asetnya dengan baik (Mudawamah et al., 2018). Beberapa penelitian membuktikan bahwa semakin tinggi Financial target yang ditetapkan perusahaan maka akan memicu manajer untuk melakukan Financial statement fraud (Septriani \& Handayani, 2018) dan (Achmad \& Pamungkas, 2018). Dari penjelasan di atas maka dapat ditarik hipotesis sebagai berikut.

$\mathrm{H}_{2}$ : Financial target berpengaruh positif terhadap Financial statement fraud.

Berdasarkan ISA No. 240 (2009) external pressure merupakan aktivitas berlebihan dari pihak manajemen perusahaan guna memenuhi keinginan pihak ketiga. Aktivitas berlebihan tersebut timbul karena adanya persaingan yang ketat antar industri perbankan dan menyebabkan manajer harus mencari tambahan dana eksternal agar perusahaan tetap kompetitif (Achmad \& Pamungkas, 2018). Demi menjaga perusahaan tetap kompetitif maka, manajer berusaha mencari tambahan dana dengan cara menerbitkan laporan keuangan yang baik sehingga investor berkenan memberikan dana kepada perusahan. Menurut Dewi \& Eveline (2017) menyatakan bahwa investor cenderung menyukai laba yang stabil. Oleh karena itu, demi mendapatkan tambahan dana dari investor, perbankan dapat melakukan Financial statement fraud dengan cara mengelola LLP agar dapat menghasilkan laba yang sesuai dengan keinginan investor. 
Indikator pengukuran external pressure dapat menggunakan rasio LEV. Rasio LEV dapat menunjukkan persentase dana perusahaan yang diperoleh dari pihak kreditur/nasabah (Brigham \& Houston, 2014:143). Rasio LEV yang tinggi menunjukkan bahwa utang perusahaan yang sebagian besar meliputi deposito, giro dan simpanan dijaminkan oleh aset perusahan yang kecil (Mangeka \& Rahayu, 2018). Hal tersebut akan menimbulkan kekhawatiran bagi nasabah, karena jika perusahaan bangkrut maka dana nasabah tersebut akan hilang. Hal tersebut tentunya akan mengganggu stabilitas ekonomi (Ozili \& Thankom, 2018). Oleh karena itu, manajer akan melakukan Financial statement fraud melalui earnings management dengan cara pengelolaan LLP. Beberapa penelitian membuktikan bahwa external pressure berpengaruh positif terhadap Financial statement fraud (Hidayatullah \& Praptoyo, 2018), (Yesriani \& Rahayu, 2017) (Achmad \& Pamungkas, 2018) dan (Utama et al., 2018). Berdasarkan penjelasan di atas maka, dapat ditarik hipotesis sebagai berikut.

$\mathrm{H}_{3}$ : External pressure berpengaruh positif terhadap Financial statement fraud.

Kondisi yang menyebabkan sistem pengendalian perusahaan berjalan tidak baik disebut sebagai ineffective monitoring (Septriani \& Handayani, 2018). Sistem pengendalian internal perusahaan yang buruk dapat memberikan opportunity bagi manajer untuk melakukan Financial statement fraud (Utama et al., 2018). Menurut ISA No. 240 (2009) ineffective monitoring disebabkan oleh dominasi yang berlebihan oleh 1 orang dalam perusahaan dan kurangnya pengawasan dari pihak perusahaan. Pengawasan pengendalian internal perusahaan merupakan tugas dewan komisaris independen (Taco \& Ilat, 2017).

Apabila dewan komisaris independen tidak dapat menjalankan tugasnya dengan baik maka, dapat memicu terjadinya Financial statement fraud. Selain itu, menurut Ghafoor et al. (2018) kurangnya jumlah dewan komisaris juga dapat menandakan adanya Financial statement fraud. Hal ini disebabkan karena kurangnya jumlah pengawas perusahaan sehingga memberikan opportunity bagi manajer untuk melakukan Financial statement fraud melalui earnings management karena pengawasan yang lebih longgar. Beberapa penelitian membuktikan bahwa ineffective monitoring berpengaruh negatif terhadap Financial statement fraud (Septriani \& Handayani, 2018) dan (Ghafoor et al., 2018). Dari penjelasan di atas maka, dapat ditarik hipotesis penelitian sebagai berikut.

$\mathrm{H}_{4}$ : Ineffective monitoring berpengaruh negatif terhadap Financial statement fraud.

Berdasarkan ISA No. 240 (2009) Financial statement fraud pada umumnya terjadi karena perilaku manajer yang berusaha menyembunyikan laporan keuangan yang sesungguhnya dari auditor. Hal tersebut disebabkan karena adanya perbedaan kepentingan antara manajer dan auditor. Berdasarkan ISA No. 240 (2009) sudah menjadi tanggungjawab auditor untuk mengaudit laporan keuangan yang sesuai dengan peraturan yang berlaku. Akan tetapi, manajer tidak dapat membiarkan hal tersebut terjadi karena terdapat dorongan dalam diri manajer untuk memenuhi keuntungan bagi dirinya sendiri. Hal tersebut akhirnya menimbulkan situasi yang tegang antara manajer dan auditor yang menyebabkan manajer melakukan change of auditor untuk menutupi Financial statement fraud melalui earnings management. Penelitian yang dilakukan oleh Lou \& Wang (2009) dalam Utama et al. (2018) menyatakan bahwa perusahaan dapat melakukan change of auditor untuk menutupi Financial statement fraud 
yang dilakukan. Beberapa penelitian membuktikan bahwa change of auditor berpengaruh positif terhadap Financial statement fraud (Utama et al., 2018) dan (Ghafoor et al., 2018). Dari penjelasan di atas maka dapat ditarik kesimpulan sebagai berikut.

$\mathrm{H}_{5}$ : Change of auditor berpengaruh positif terhadap Financial statement fraud.

\section{METODE PENELITIAN}

Penelitian ini dilakukan pada perusahaan perbankan yang terdaftar di bursa efek masing- masing negara yaitu SGX, MYX, SET, PSE dan IDX pada periode tahun 2015 - 2019. Penelitian ini menggunakan laporan tahunan perusahaan perbankan yang diterbitkan di masing-masing bursa efek setiap negara atau di web resmi perusahaan. Populasi dalam penelitian ini adalah perusahaan perbankan komersial non-syariah yang terdaftar di SGX, MYX, SET, PSE dan IDX. Jumlah perbankan komersial non-syariah di setiap negara sebesar, Singapura 3 perusahaan, Malaysia 8 perusahaan, Thailand 10 perusahaan, Filipina 12 perusahaan dan Indonesia 41 perusahaan. Jumlah seluruh populasi sebesar 74 perusahaan. Metode pengambilan sampel menggunakan purposive sampling dengan syarat yaitu perusahaan perbankan yang terdaftar di SGX, MYX, SET, PSE dan IDX selama periode tahun penelitian 2015 - 2019, perusahaan perbankan yang menerbitkan dan memiliki laporan tahunan lengkap serta telah diaudit, perusahaan perbankan yang memiliki pencatatan laporan keuangan periode Januari sampai Desember dari 2015 - 2019.

Financial statement fraud diproksikan menggunakan earning management yang diukur dengan LLP. LLP tercatat dalam laporan laba rugi sebagai beban yang perlu disetujui oleh manajer (Isa et al., 2018) dan (Hatane et al., 2018). Oleh karena kendali LLP terdapat di tangan manajer, maka pemanfaatannya dapat disesuaikan dengan keinginan manajer. LLP dibagi dalam 2 bentuk yaitu DLLP (discretionary loan loss provision) dan NDLPP (non-discretionary loan loss provision). Komponen discretionary terjadi karena adanya penurunan aset akibat campur tangan manajemen sedangkan komponen NDLLP terjadi karena adanya penurunan aset secara alami (Kanagaretnam et al., 2004).

Penelitian ini bertujuan untu menguji pengaruh variabel independen yaitu Financial stability, Financial target, external pressure, ineffective monitoring dan change of auditor terhadap variabel dependen yaitu Financial statement fraud. Metode analisis data menggunakan analisis regresi linier berganda. Berikut adalah persamaan regresi linier berganda.

DLLPit $=B 0+B 1$ Financial stability + $\$$ Financial target + B3external pressure+ B4ineffective monitoring + B5change of auditor $+\varepsilon$

Berikut penjelasan persamaan regresi linier berganda.

DLLPit = discretionary accruals perusahaan i pada periode $\mathrm{t}$.

B0 $\quad=$ Koefisien konstanta regresi.

$ß 1, ß 2, ß 3, ß 4$,dan $\$ 5=$ Koefisien masing-masing variabel independen.

$\varepsilon \quad=$ Error. 
Tabel 1. Definisi Operasional

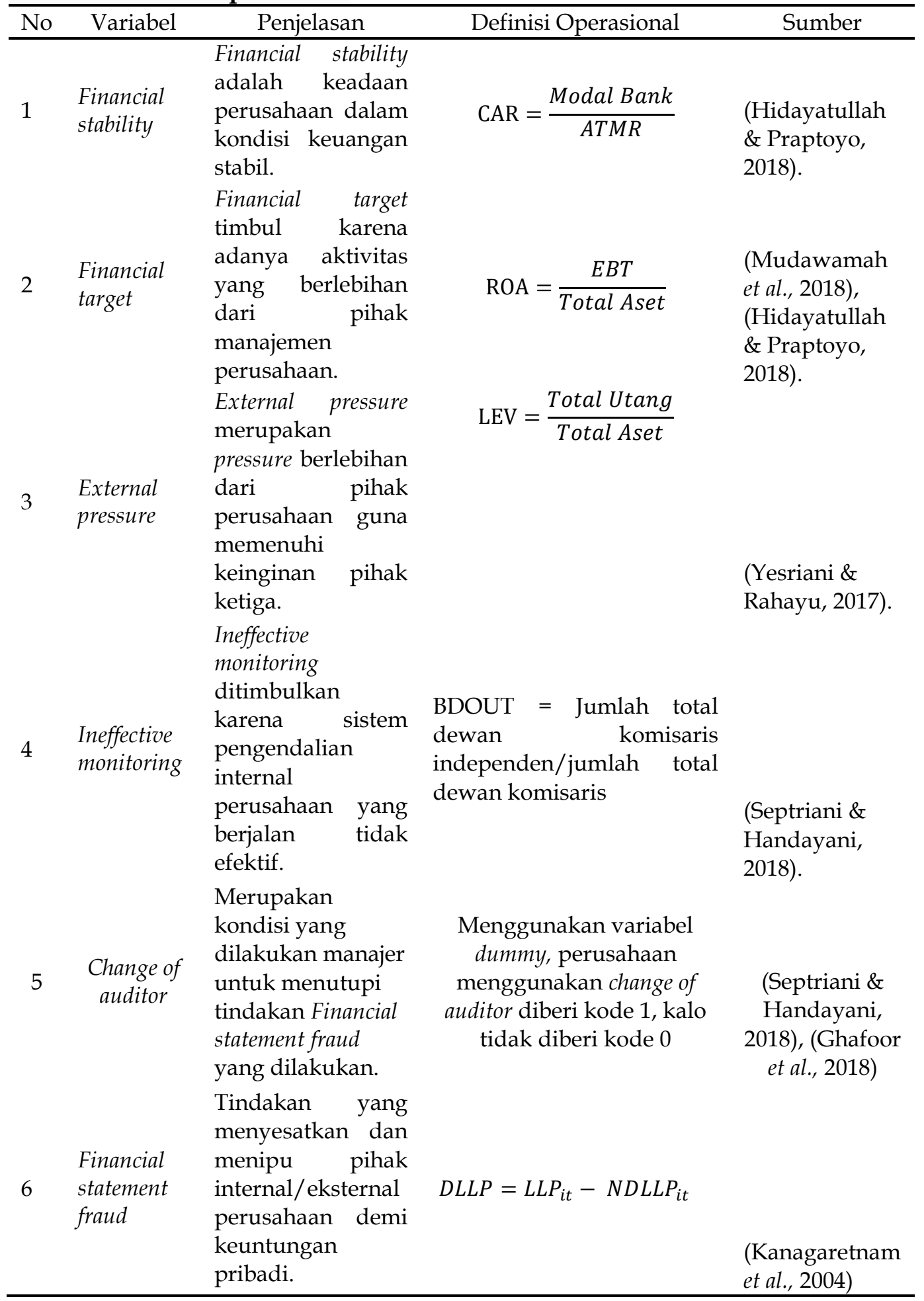

Sumber: Data Penelitian, 2020

HASIL DAN PEMBAHASAN

Penelitian ini Pengambilan sampel dalam penelitian menggunakan metode nonprobability sampling dengan teknik purposive sampling. Populasi dalam penelitian 
ini sebanyak 74 perusahaan perbankan selama rentan waktu 2015 - 2019 dengan total data populasi sebesar 370 data. Setelah dilakukan purposive sampling sampling jumlah perusahaan menjadi 66 perusahaan dengan 330 data yang diolah. Berikut adalah proses seleksi sampel dalam penelitian.

\section{Tabel 2. Hasil Sampel Penelitian}

\begin{tabular}{|c|c|c|}
\hline No. & Kriteria & Jumlah Perusahaan \\
\hline 1 & $\begin{array}{l}\text { Perusahaan perbankan komersial non- } \\
\text { syariah yang terdaftar di SGX, MYX, SET, } \\
\text { PSE dan IDX }\end{array}$ & 74 \\
\hline 2 & $\begin{array}{l}\text { Perusahaan perbankan komersial non- } \\
\text { syariah yang menerbitkan dan memiliki } \\
\text { laporan tahunan lengkap serta telah } \\
\text { diaudit. }\end{array}$ & (5) \\
\hline 3 & $\begin{array}{l}\text { Perusahaan perbankan komersial non- } \\
\text { syariah yang pelaporan keuangan berakhir } \\
\text { pada } 31 \text { Desenber } 2015 \text { - } 31 \text { Desember } 2019 \text {. }\end{array}$ & (3) \\
\hline & Jumlah sampel perusahaan & 66 \\
\hline & Jumlah data yang diolah & 330 \\
\hline
\end{tabular}

Sumber: Data Penelitian, 2020

Berikut adalah hasil statistik deskriptif yang tercantum dalam Tabel 3. Financial stability diproksikan dengan rasio kecukupan modal, dimana semakin rendah Financial stability maka semakin tinggi Financial statement fraud. Nilai minimum sebesar 0,80 yang diperoleh oleh Bank Banten sedangkan nilai maksimum sebesar 0,66 yang diperoleh oleh Bank Ina. Nilai rata-rata sebesar 0,20 yang berarti semua perbankan di Singapura, Malaysia, Thailand, Filipina dan Indonesia telah memenuhi rata-rata minimum rasio kecukupan modal. Standar deviasi sebesar 0,07 lebih kecil dari nilai rata-rata yang artinya karakteristik sampel tidak bervariasi sehingga data menyebar merata pada perusahaan perbankan.

Tabel 3. Hasil Statistik Deskriptif

\begin{tabular}{|c|c|c|c|c|c|}
\hline & $\mathrm{N}$ & Min & Max & Mean & $\begin{array}{c}\text { Std. } \\
\text { Deviation }\end{array}$ \\
\hline financial_stability & 330 & 0,08 & 0,66 & 0,20 & 0,07 \\
\hline financial_target & 330 & $-0,10$ & 0,04 & 0,01 & 0,02 \\
\hline external_pressure & 330 & 0,60 & 0,95 & 0,86 & 0,05 \\
\hline ineffective_monitoring & 330 & 0,20 & 1,00 & 0,52 & 0,15 \\
\hline change_of_auditor & 330 & 0 & 1,00 & 0,42 & 0,50 \\
\hline $\begin{array}{l}\text { Financial statement } \\
\text { fraud }\end{array}$ & 330 & $-0,04$ & 0,08 & -0.00 & 0,01 \\
\hline Valid N (listwise) & 330 & & & & \\
\hline
\end{tabular}

Financial target diproksikan dengan rasio ROA, dimana semakin tinggi Financial target maka semakin tinggi Financial statement fraud. Nilai minimum sebesar -0,10 diperoleh oleh Bank Banten dan nilai maksimum sebesar 0,04 diperoleh oleh Bank BCA. Nilai rata-rata sebesar 0,01 dan standar deviasi sebesar 0,02. Nilai minimum minus dikarenakan Bank Banten mengalami kerugian. Akan tetapi, nilai rata-rata perusahaan mendekati nilai maksimum yang berarti perbankan di Singapura, Malaysia, Thailand, Filipina dan Indonesia dapat 
mengelola asetnya dengan baik untuk memaksimalkan laba. Standar deviasi sebesar 0,02 lebih besar dari nilai rata-rata yang artinya karakteristik sampel bervariasi sehingga data menyebar tidak merata pada perusahaan perbankan.

External pressure diproksikan dengan rasio LEV, dimana semakin tinggi external pressure maka semakin tinggi Financial statement fraud. Nilai minimum sebesar 0,60 yang diperoleh oleh Bank Dinar dan nilai maksimum sebesar 0,95 yang diperoleh oleh Bank Banten. Nilai rata-rata sebesar 0,86 dan standar deviasi sebesar 0,05. Nilai maksimum diperoleh Bank Banten karena adanya penurunan kinerja bank di tahun 2015 yang disebabkan oleh perlambatan kondisi perekonomian. Berdasarkan nilai rata-rata yang mendekati nilai maksimum yang berarti perbankan di Singapura, Malaysia, Thailad, Filipina dan Indonesia memiliki rasio LEV yang cukup tinggi. Nilai standar deviasi sebesar 0,05 lebih kecil dari rata-rata yang artinya karakteristik sampel tidak bervariasi sehingga data menyebar merata pada perusahaan perbankan.

Ineffective monitoring diproksikan dengan rasio proporsi dewan komisaris independen, dimana semakin rendah ineffective monitoring maka akan meningkatkan Financial statement fraud. Nilai minimum sebesar 0,2 diperoleh Bank Union dan nilai maksimum sebesar 1 diperoleh Bank Banten. Bank banten memeproleh nilai ineffective monitoring yang artinya bank telah melampaui jumlah minimum dewan komisaris independen. Nilai rata-rata sebesar 0,52 dan standar deviasi sebesar 0,15. Nilai rata-rata 0,52 menunjukkan bahwa rata-rata bank telah memenuhi ketentuan minimum jumlah dewan komisaris independen. Nilai standar deviasi sebesar 0,15 lebih kecil dari rata-rata yang artinya karakteristik sampel tidak bervariasi sehingga data menyebar merata pada perusahaan perbankan.

Change of auditor yang semakin tinggi akan meningkatkan Financial statement fraud. Terdapat 139 perusahaan yng melakukan change of auditor atau sekitar $42.12 \%$ perusahaan melakukan change of auditor. Sedangkan 191 perusahaan tidak melakukan change of auditor atau sekitar 57.88\%. Sebesar 125 perbankan di Indonesia melakukan change of auditorsehingga hal tersebut perlu diperhatikan oleh pemerintah karena dapat mengindikasikan perusahaan melakukan Financial statement fraud.

Financial statement fraud diukur menggunakan perhitungan DLLP (discretionary loan loss provisions) dimana jumlah DLLP dapat dimanfaatkan manajer untuk menaikkan/menurunkan laba melalui pengelolaan jumlah LLP (Kanagaretnam et al., 2004). Nilai mininimum sebesar -0,04 yang diperoleh Bank Philtrust dan nilai maksimum sebesar 0,08 yang diperoleh oleh Bank MNC. Hal tersebut dikarenakan pada tahun 2017 Bank MNC sedang berfokus menghapus kredit bermasalahnya dan menyebabkan kerugian. Jumlah rata-rata Financial statement fraud sebesar -0,00 dan standar deviasi sebesar 0,01. Hal tersebut berarti perbankan di Singapura, Malaysia, Thailand, Filipina dan Indonesia cenderung melakukan earnings management dengan cara menurunkan jumlah LLP agar dapat memaksimalkan laba. . Standar deviasi sebesar 0,01 lebih besar dari nilai rata-rata yang artinya karakteristik sampel bervariasi sehingga data menyebar tidak merata pada perusahaan perbankan. 
Tabel 4. Hasil Uji Regresi Linier Berganda

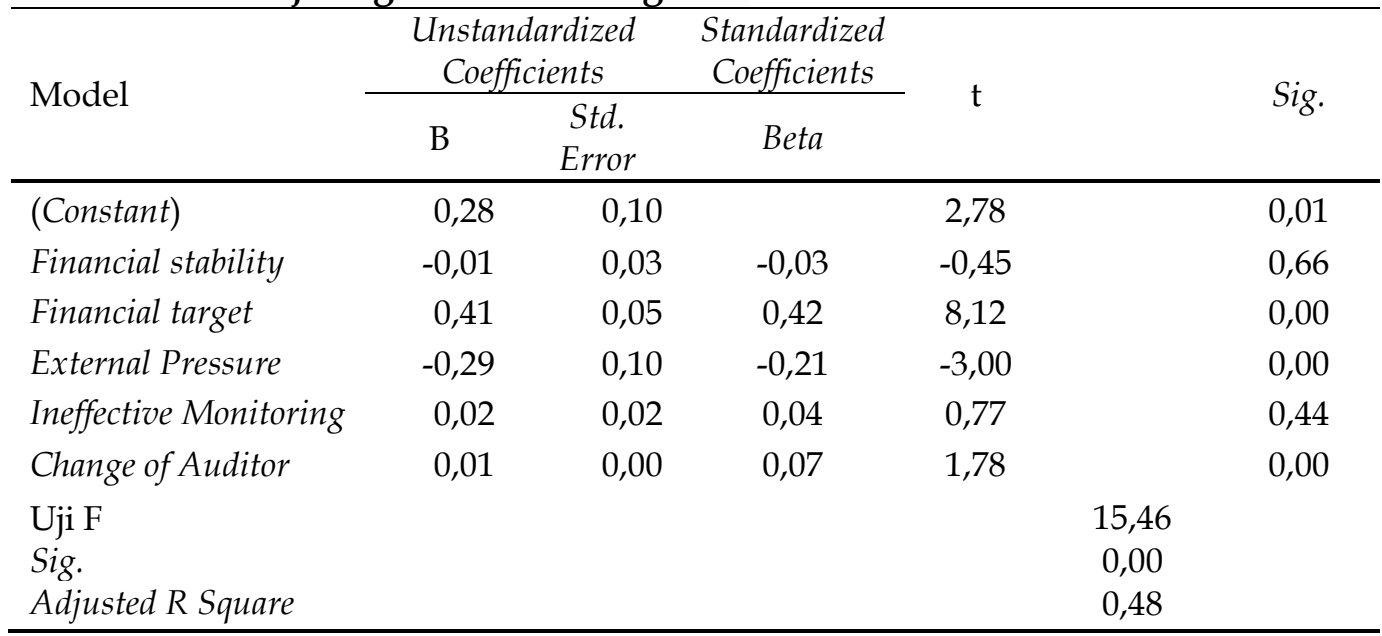

Sumber: Data Penelitian, 2020

Berdasarkan Tabel 4, maka dapat dirumuskan persamaan regresi yang baru sebagai berikut.

DLLPit $=0,28-0,01$ Financial stability $+0,41$ Financial target $-0,29$ external pressure $+0,02$ ineffective monitoring $+0,01$ change of auditor.

Hasil uji $\mathrm{F}$ (goodness of fit) menunjukkan tingkat signifikansi sebesar 0,00 yang lebih kecil dari nilai $\alpha=0,05$ sehingga model persamaan dalam penelitian ini layak untuk digunakan. Nilai koefisien determinasi menggunakan nilai adjusted $\mathrm{R}$ square sebesar 0.48 yang berarti $48 \%$ persen variabel independen Financial stability, Financial target, external pressure, ineffective monitoring dan change of auditor dapat dijelaskan oleh variabel dependen Financial statement fraud. Nilai sisanya sebesar $52 \%$ menunjukkan bahwa variabel penelitian dipengaruhi oleh faktor lain diluar regresi.

Berdasarkan hasil olah data yang ditunjukkan dalam Tabel 4, variabel Financial stability memiliki tingkat signifikansi sebesar 0,66. Oleh karena itu, hipotesis pertama ditolak karena Financial stability tidak berpengaruh terhadap Financial statement fraud. Hal tersebut menunjukkan bahwa rasio kecukupan modal tidak mempengaruhi perusahaan untuk melakukan Financial statement fraud melalui earnings management. Hasil penelitian ini sejalan dengan penelitian Vishnani et al. (2019), tetapi hasil tersebut tidak sejalan dengan hasil penelitian Hidayatullah \& Praptoyo (2018) yang menunjukkan bahwa Financial stability berpengaruh terhadap Financial statement fraud.

Hasil penelitian ini tidak sejalan dengan komponen pressure dalam fraud triangle theory, yang menyatakan bahwa pressure yang diproksikan melalui Financial stability dapat mempengaruhi Financial statement fraud. Hal tersebut terjadi karena, menurut Vishnani et al. (2019) perbankan merupakan perusahaan yang diatur ketat, sehingga perbankan harus mematuhi regulasi yang berlaku. Selain itu, regulasi yang ketat membatasi perilaku manajer untuk melakukan earnings management karena pengawasan yang diberikan juga semakin ketat. Hal tersebut dapat dilihat dari nilai rata-rata yang menunjukkan bahwa bank di Singapura, Malaysia, Thailand, Filipina dan Indonesia telah melampaui rata-rata rasio minimum kecukupan modal. Bank yang telah malampaui rasio minimum 
kecukupan modal, tidak dapat mengindikasikan terjadinya Financial statement fraud (Vishnani et al., 2019).

Hasil pengolahan data dalam Tabel 4, menunjukkan bahwa variabel Financial target memiliki nilai signifikansi sebesar 0,00 sehingga hipotesis kedua dalam penelitian ini diterima. Hal tersebut menunjukkan bahwa semakin tinggi Financial target yang diproksikan melalui ROA dapat mempengaruhi Financial statement fraud melalui earnings management. Hasil penelitian sejalan dengan penelitian yang dilakukan oleh (Septriani \& Handayani, 2018), (Achmad \& Pamungkas, 2018), dan (Vishnani et al., 2019). ROA yang semakin tinggi mengindikasikan perusahaan melakukan Financial statement fraud melalui earnings management. Cara yang digunakan adalah menaikkan jumlah LLP agar dapat memaksimalkan laba perusahaan. Hasil tersebut sejalan dengan fraud triangle theory yang menyatakan bahwa pressure yang tinggi akibat Financial target yang berlebihan dari pihak manajemen dapat mempengaruhi Financial statement fraud.

Hasil pengolahan data dalam Tabel 4, menunjukkan bahwa variabel external pressure memiliki nilai signifikansi sebesar 0,00 dengan arah koefisien regresi sebesar $-0,29$. Oleh karena itu, hipotesis ketiga dalam penelitian ini ditolak. Arah koefisien regresi yang negatif berarti external pressure yang diproksikan melalui rasio LEV yang tinggi menyebabkan indikasi Financial statement fraud menurun. Hasil penelitian tidak sejalan dengan penelitian yang dilakukan oleh Hidayatullah \& Praptoyo (2018), Yesriani \& Rahayu (2017), Achmad \& Pamungkas (2018) dan Utama et al. (2018). Hasil penelitian sejalan dengan penelitian yang dilakukan oleh Septriani \& Handayani (2018).

Hasil penelitian menunjukkan bahwa external pressure tidak berpengaruh terhadap Financial statement fraud. Hal tersebut terjadi karena perusahaan perbankan merupakan industri yang diatur sehingga tingkat pengawasan yang diberikan juga tinggi. Selain itu, apabila tingkat utang perusahaan yang tinggi dapat mengkhawatirkan nasabah karena dana yang diberikan dapat hilang. Akan tetapi, karena perbankan merupakan industri yang diatur dan diawasi, dana nasabah tersebut telah dijaminkan oleh lembaga penjamin simpanan sehingga apabila bank tidak mampu mengembalikan dana nasabah, maka lembaga penjamin simpanan yang akan membayarnya. Adanya penjagaan eksternal yang ketat dapat membatasi manajer untuk melakukan Financial statement fraud melalui earnings management. Oleh karena pressure yang diproksikan dengan external pressure tidak dapat meningkatkan Financial statement fraud.

Hasil pengolahan data dalam Tabel 4, menunjukkan bahwa variabel ineffective monitoring memiliki nilai signifikansi sebesar 0,44 sehingga hipotesis keempat dalam penelitian ditolak. Hasil penelitian tidak mendukung teori fraud triangle komponen opportunity. Hal tersebut dikarenakan rata-rata proporsi dewan komisaris independen di perbankan telah memenuhi peraturan minimum jumlah dewan komisaris independen. Oleh karena itu jumlah pengawas perusahaan sudah sesuai dengan peraturan, sehingga manajer tidak memiliki opportunity untuk melakukan Financial statement fraud.

Selain itu berdasarkan penelitian yang dilakukan oleh Yesriani \& Rahayu (2017) menunjukkan bahwa tugas dewan komisaris independen tidak berjalan 
dengan baik karena adanya campur tangan pihak ketiga yang membatasi perilaku dewan komisaris independen. Pembatasan perilaku tersebut berdampak pada kinerja dewan komisaris independen yang dapat menyebabkan penurunan kualitas kerja. Hal tersebut menyebabkan dewan komisaris independen tidak dapat mendeteksi Financial statement fraud melalui earnings management. Hasil penelitian tidak sejalan dengan penelitian yang dilakukan oleh Septriani \& Handayani, (2014) dan Ghafoor et al. (2018). Hasil penelitian sejalan dengan temuan yang dilakukan oleh Yesriani \& Rahayu (2017).

Hipotesis kelima dalam penelitian menunjukkan bahwa variabel change of auditor berpengaruh positif terhadap Financial statement fraud. Hasil pengolahan data dalam Tabel 4, menunjukkan bahwa nilai signifikansi sebesar 0.00 yang lebih kecil dari $a=0.05$ yaitu $0.00<0.05$ sehingga hipotesis ketiga dalam penelitian diterima. Artinya, semakin sering perusahaan melakukan change of auditor maka dapat mengindikasikan Financial statement fraud melalui earnings management. Hasil penelitian sejalan dengan penelitian yang dilakukan oleh Ghafoor et al. (2018) dan Utama et al. (2018) yang menyatakan bahwa change of auditor berpengaruh positif terhadap Financial statement fraud.

Semakin sering perusahaan melakukan change of auditor maka semakin tinggi terjadinya Financial statement fraud. Hal tersebut mendukung fraud triangle theory komponen rationalization. Motivasi manajer melakukan change of auditor merupakan pembenaran atas tindakan kecurangan yang dilakukannya (Utama et al., 2018). Manajer melakukan tindakan tersebut agar auditor tidak mengetahui Financial statement fraud melalui earnings management yang dilakukan oleh manajer.

\section{SIMPULAN}

Hasil penelitian ini menunjukkan bahwa Financial stability tidak mempengaruhi Financial statement fraud pada perusahaan perbankan di Singapura, Malaysia, Thailand, Filipina dan Indonesia selama tahun 2015 - 2019. Hal tersebut menunjukkan bahwa rasio kecukupan modal tidak mempengaruhi terjadinya Financial statement fraud melalui pengelolaan LLP.

Financial target berpengaruh positif terhadap Financial statement fraud pada perusahaan perbankan di Singapura, Malaysia, Thailand, Filipina dan Indonesia selama tahun 2015 - 2019. Hasil tersebut membuktikan bahwa pressure karena penetapan Financial target yang tinggi dapat menyebabkan manajer melakukan Financial statement fraud melalui earnings management. Manajer dapat mengelola LLP untuk memaksimalkan laba perusahaan.

External pressure tidak berpengaruh terhadap Financial statement fraud pada perusahaan perbankan di Singapura, Malaysia, Thailand, Filipina dan Indonesia selama tahun 2015 - 2019. Hasil tersebut membuktikan bahwa manajer tidak dapat dengan bebas melakukan Financial statement fraud melalui earnings management dengan cara mengelola LLP karena adanya pengawasan yang ketat dari pihak eksternal.

Ineffective monitoring tidak berpengaruh terhadap Financial statement fraud pada perusahaan perbankan di Singapura, Malaysia, Thailand, Filipina dan Indonesia selama tahun 2015 - 2019. Hasil penelitian membuktikan bahwa proporsi dewan komisaris independen tidak dapat mengindikasikan terjadinya 
Financial statement fraud, karena ada atau tidaknya dewan komisaris independen tidak dapat mempengaruhi terjadinya Financial statement fraud melalui pengelolaan LLP.

Change of auditor berpengaruh positif terhadap Financial statement fraud pada perusahaan perbankan di Singapura, Malaysia, Thailand, Filipina dan Indonesia selama tahun 2015 - 2019. Hasil penelitian membuktikan bahwa semakin sering perusahaan melakukan change of auditor berarti mengindikasikan terjadinya Financial statement fraud.

Keterbatasan penelitian ini adalah pengkonversian nilai mata uang setiap negara ke dalam USD Dollar yang fluktuatif, sehingga hasil olah data menunjukkan gap yang besar. Oleh karena itu, saran untuk penelitian berikutnya adalah fokus pada negara yang memiliki kondisi ekonomi serupa agar perbandingan data dalam penelitian tidak melenceng jauh. Penelitian berikutnya dapat menggunakan bank yang sama besarnya sehingga hasil penelitian dapat homogen. Penelitian berikutnya dapat menggunakan perusahaan sektor lainnya seperti perusahaan manufaktur dan perusahaan milik negara. Penelitian berikutnya dapat menambahkan proksi pengukuran variabel yang cocok dengan perbankan, seperti rasio LDR.

Bagi pemerintah dan investor dapat lebih berhati - hati dalam mengambil keputusan. Pemerintah perlu meningkatkan pengawasan melalui pembentukan regulasi kepada perusahaan perbankan agar tidak memanfaatkan laporan keuangan untuk kepentingan pribadi, khususnya untuk variabel change of auditor. Investor perlu memperhatikan faktor-faktor yang dapat memicu terjadinya Financial statement fraud sebelum berinvestasi, seperti Financial target dan change of auditor. Investor perlu untuk berpikir skeptis terhadap profitabilitas yang dihasilkan perusahaan, karena tingkat profitabilitas dapat memicu terjadinya Financial statement fraud.

\section{REFERENSI}

15 th Global Fraud Survey. (2019). Integrity in the spotlight: the future of compliance. Diambil pada 19 Februari 2021 dari https:/ / fraudsurveys.ey.com/ey-global-fraud-survey-2018

Achmad, T \& Pamungkas, I. D. (2018). Fraduelent Financial Reporting Based of Fraud Diamond Theory: A Study of the Banking Sector in Indonesia. Jurnal Ilmiah Akuntansi Fakultas Ekonomi, 4(2), 135 - 150. https://doi.org/ 10.34204/jiafe.v4i2.1112

Asmah, A. E., Atuilik, W. A \& Ofiri, D. (2020). Antecendents and Consequences of Staff Related Fraud in The Ghana Banking Industry. Journal of Financial Crime, 27 (1), 188 - 201. http:/ / dx.doi.org/10.1108/JFC-03-2019-0034

Association of Certified Fraud Examiners. (2020). Report to the Nation on Occupational Fraud and Abuse (On-line). Diambil pada 11 Maret 2020 dari www.acfe.com.

AU Section 316. (2002). Consideration of Fraud in a Financial Statement Audit. Diambil pada 29 Februari 2020 dari www.aicpa.org.

BIS. (2001). The New Basel Capital Accord: An Explanatory Note. Bank for International Settlements, 1 - 16.

Brigham \& Houston. (2014). Dasar-Dasar Manajemen Keuangan. Jakarta: Salemba Empat. 
Ceic Data. (2020). Capital Adequacy Ratio. Diambil pada 19 Februari 2021 dari Capital Adequacy Ratio (ceicdata.com)

CNBC. (2017). Drama Bank Bukopin: Modifikasi Kartu Kredit dan Rights Issue. Diambil pada $18 \quad$ September 2020 dari https://www.cnbcindonesia.com/market/20180427144303-17-

12810/drama-bank-bukopin-kartu-kredit-modifikasi-dan-rights-issue

Cressey, D. (1953). Other people's money: A Study in the Social Psychology of Embezlement. Glencoe, II: Free Press.

Dewi, S. P \& Eveline. (2017). Faktor-Faktor yang Mempengaruhi Discretionary Loan Loss Provisions Pada Perusahaan Perbankan yang Terdaftar di Bursa Efek Indonesia, Jurnal Manajemen, 21(3), 434 - 453. http://dx.doi.org/10.24912/jm.v21i3.261

Embuningtyas, S. S. (2018). Discretionary Loan Loss Provisions Sebagai Alat Deteksi Manajemen Laba Pada Perbankan Konvensional di Indonesia. Jurnal Riset Keuangan dan Akuntansi, 4(1), $15 \quad$ - 29. https:// doi.org/10.25134/jrka.v4i1.1332

Ghafoor, A., Zainudin, R \& Mahdzan, N. S. (2018). Factors Elicting Corporate Fraud in Emerging Markets: Case of Firms Subject to Enforcement Actions in Malaysia. Journal of Business Ethics, 587 - 608. https://doi.org/10.1007/s10551-018-3877-3

Ha, D., Gillet, P., Le, P., \& Vo, D. T. (2018). Banking Integration in ASEAN-6: An Empirical Investigation. Economic Modelling, 91, 705 - 719. https://doi.org/10.1016/j.econmod.2019.09.017

Hatane, S. E., Octavia, F \& Florentina, J. (2019). The Comparison of Earninngs Management Practices in Indonesia's Islamic Banks and Conventional Banks. Advances in Economics and Management Research, 69, 127 - 131. https://dx.doi.org/10.2991/teams-18.2019.22

Hidayatullah, S \& Praptoyo, S. (2018). Deteksi Financial statement fraud Dengan Analisis Fraud Triangle. Jurnal Ilmu dan Riset Akuntansi, 7 (1), 1 - 20.

Husen, T. I. (2017). Pengaruh Efisiensi Biaya Perbankan di Kawasan ASEAN-5. Jurnal Bisnis dan Kajian Strategi Manajemen, 1(2), pp. 63 - 76. https://doi.org/10.35308/jbkan.v1i2.901

Isa, M. Y. M., Choong, Y. V., Fie, D. Y. G \& Rashid, M. Z. H. A. (2018). Determinant of Loan Loss Provisions of Commercial Banks in Malaysia. Journal of Financial Reporting and Accounting, 16 (1), 24 - 48. https://doi.org/10.1108/JFRA-03-2015-0044

Kanagaretnam K., Hamilton \& Lobo, G. J. (2004). Earning Management to Reduce Earnings Variability: Evidence from Bank Loan Loss Provisions. Review of Accounting and Finance, 128 - 148. https:/ / doi.org/10.1108/eb043399

KPMG. (2019). Global Banking Fraud Survey. Diambil pada 11 Maret 2020 dari https://home.kpmg/xx/en/home/campaigns/2019/12/global-annualreview.html.

Kurniawansyah, D. (2018). Apakah Manajemen Laba Termasuk Kcurangan? Analisis Literatur. Jurnal Riset Akuntansi dan Bisnis Airlangga, 3(1), 341 - 356. http://dx.doi.org/10.31093/jraba.v3i1.97

Lokanan, M \& Sharma, S. (2018). A Fraud Triangle Analysis of the Libor Fraud. Journal of Forensic E Investigative Accounting, 10(2), 187 - 212. 
Lou, Y.I., dan Wang, M.L. (2009). Fraud Risk Factor of the Fraud Triangle Assesing the Likelihood of Fraudulent Financial Reporting. Journal of Business and Economic Research, 7(2), 62-66.

Mangeka, D. P \& Rahayu, Y. (2020). Pengaruh Fraud Triangle Dalam Mendeteksi Financial statement fraud. Jurnal Ilmu dan Riset Akuntansi, 9 (2), 1 - 21.

Mcnicholas, M. F \& Stubben, S. R. (2018). Research Design Issues in Studies Using Discretionary Accruals. A Journal of Accounting, Finance and Business Studies, 54 (22), 227 - 246. https:/ / doi.org/10.1111/abac.12128

Mudawamah, S., Wijone, T. \& Hidayat, R. R. (2018). Analisis Rasio Keuangan Untuk Menilai Kinerja Keuangan Perusahaan (Studi Pada Bank Usaha Milik Negara yang Terdaftar di Bursa Efek Indonesia Tahun 2013 - 2015). Jurnal Administrasi Bisnis, 54(1), 20 - 29. administrasibisnis.studentjournal.ub.ac.id

Noman, A. H. M., Gee, C. S \& Isa, C. R. (2018). Does Bank Regulation Matter on The Relationship Between Competition and Financial stability? Evidence from Southeast Asian Countries. Pacific-Basin Finance Journal, 144 - 161. https://doi.org/10.1016/j.pacfin.2018.02.001

Ozili, P. \& Arun, T. (2018). Income smoothing among European systemic and non-systemic banks. The British Accounting Review, 5(5), 539 - 558. https://doi.org/10.1016/j.bar.2018.03.001

Ramly, Z., Chan, S.G., Mustapha, M. Z. \& Sapiei, N. S. (2015). Women on Boards and Bank Efficiency in ASEAN-5: The Moderating Role of Independent Directors. Review of Managerial Science, 225 - 250. https://doi.org/10.1007/s11846-015-0186-4

Rochmadhona, B. N., Suganda, T. R. \& Chayadi, S. (2018). The Competitive Advantage Between Intellectual Capital and Financing Performance of Banking Sector in ASEAN. Pacific-Basin Finance Journal, 144 - 161. https://doi.org/10.26905/jkdp.v22i2.2060

Selvarajan, S. K., Rahim, R., \& Marikan, D. A. (2018). Does Financial Liberalization Foster Economic Growth? Empirical Evidence from ASEAN6 Countries. International Journal of Engineering \& Technology, 3(21), 102-108. https://doi.org/ 10.14419/ijet.v7i3.21.17103

Septriani, Y. \& Handayani, D. (2018). Mendeteksi Kecurangan Laporan Keuangan dengan Analisis Fraud Pentagon. Jurnal Akuntansi, Keuangan dan Bisnis, 11(1), 11-23.

Taco, C. \& Ilat, V. (2017). Pengaruh Earning Power, Komisaris Independen, Dewan Direksi, Komite Audit dan Ukuran Perusahaan Terhadap Manajemen Laba Pada Perusahaan Manufaktur yang Terdaftar di Bursa Efek Indonesia. Jurnal EMBA, 4(4), $887 \quad$ - 884. https:// doi.org/10.35794/emba.v4i4.14514

The Edge Market. (2020). 1MDB ex-CEO: Najib pressured me to replace 1MDB auditor. Diambil pada 26 November 2020 dari 1MDB ex-CEO: Najib pressured me to replace 1MDB auditor | The Edge Markets

Utama, I. G. P. O. S., Ramantha, I. W. \& Badera, I. D. N. (2018). Analisis Faktor Faktor dalam Perspektif Fraud Traingle Sebagai Prediktor Fraduelent Financial Reporting. E-Jurnal Ekonomi dan Bisnis Universitas Udayana, 7(1), $251-278$. 
Ventouri, A. (2018). Bank Competition and Regional Integration: Evidence from ASEAN Nations. Review of Development Finence, 8, 127 - 140. https://doi.org/10.1016/j.rdf.2018.08.002

Vishnani, S., Agarwal, S., Agarwalla, R \& Gupta, S. (2019). Earnings Management. Capital Management and Signalling Behaviour of Indian Banks. Asia-Pacific Financial Markets, 285 - 295. https://doi.org/10.1007/s10690-018-09265-x

Vousinas, G. (2019). Advancing Theory of Fraud: The S.C.O.R.E. Model. Journal of Financial Crime, 26(1), 372 - 381. https:/ / doi.org/10.1108/JFC-12-2017-0128

$\mathrm{Wu}, \mathrm{X}$. \& Wang, J. (2018). Management's Materiality Criteria of Internal Control Weaknesses and Corporate Fraud: Evidence from China. The International Journal of Accounting, 53 (1), 1-19. https://doi.org/10.1016/j.intacc.2018.02.001

Yesriani, M \& Rahayu, I. (2017). Deteksi Financial statement fraud: Pengujian dengan Fraud Diamond. Jurnal Akuntansi dan Auditing Indonesia, Vol. 21 No.1, pp. 49 - 59. http:/ / dx.doi.org/10.20885/jaai.vol21.iss1.art5 